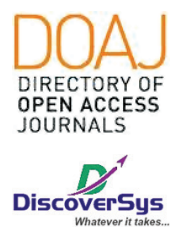

Published by DiscoverSys

\title{
Prevalensi depresi pada mahasiswa Program Studi Pendidikan Dokter semester III dan V di Fakultas Kedokteran Universitas Udayana tahun 2017
}

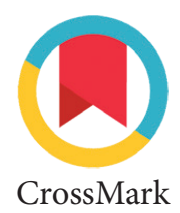

\author{
Ade Tsarina Indira, ${ }^{1 *}$ A.A Sagung Sawitri, ${ }^{2}$ Luh Ariastuti ${ }^{3}$
}

\section{ABSTRACT}

Background: Depression is general mental disorder which is based on the change of mood, loss of interest and fun and the drop energy. Depression can attack everyone including students.

Aim: This research aimed to find out prevalence of depression in medical students semester III and V in Medical Faculty of University of Udayana.

Methods: The type of research was cross-sectional descriptive research with 87 samples obtained using simple random sampling technique. This research used primary data which was obtained from questionnaire and analyzed using computer.
Results: The result of the research showed that from 87 respondents, $19.54 \%$ had mild depression, $10.34 \%$ had moderate depression, and $5.75 \%$ had severe depression. Subjects in the age of $\leq 19$ years old and $>19$ years old mostly had mild depression. Women were more often having depression than men. The number of subjects who had moderate learning pattern with mild depression was $17.6 \%$, and subjects who had hard learning pattern with mild depression was $20.7 \%$.

Conclusion: This research concludes that dominant depression level is mild depression.
${ }^{1}$ Program Studi Pendidikan Dokter Fakultas Kedokteran Universitas Udayana

${ }^{2}$ Departemen IImu Kesehatan Komunitas dan IImu Kesehatan Pencegahan Fakultas Kedokteran Universitas Udayana

${ }^{*}$ Correspondence to: Ade Tsarina Indira, Program Studi Pendidikan Dokter Fakultas Kedokteran Universitas Udayana tsarinaindira@gmail.com

Diterima: 06-04-2018

Disetujui: 15-06-2018

Diterbitkan: 01-08-2020

Key Words: depression, prevalence of depression, medical student

Cite This Article: Indira, A.T., Sawitri, A.A.S., Ariastuti, L. 2020. Prevalensi depresi pada mahasiswa Program Studi Pendidikan Dokter semester III dan V di Fakultas Kedokteran Universitas Udayana tahun 2017. Intisari Sains Medis 11(2): 892-895. D0I: 10.15562/ism.v11i2.211

\section{ABSTRAK}

Latar belakang: Depresi adalah gangguan mental umum yang ditnjukkan dengan perubahan suasana hati, kehilangan minat atau kesenangan, dan penurunan energi. Depresi dapat menyerang siapa saja termasuk mahasiswa.

Tujuan: Tujuan dari penelitian ini untuk mengetahui prevalensi depresi pada mahasiswa Program Studi Pendidikan Dokter semester III dan V di Fakultas Kedokteran Universitas Udayana.

Metode: Jenis penelitian ini adalah penelitian deskriptif cross-sectional dengan jumlah sampel sebanyak 87 orang mahasiswa semester III dan V Fakultas Kedokteran Universitas Udayana yang dipilih menggunakan teknik simple random sampling. Penelitian ini menggunakan data primer yang didapatkan dari kuesioner dan dianalisis menggunakan komputer.
Hasil: Hasil penelitian menunjukkan dari 87 responden didapatkan $19.54 \%$ mengalami depresi ringan, $10.34 \%$ mengalami depresi sedang, dan 5.75\% mengalami depresi berat. Subyek dengan usia $\leq 19$ tahun dan >19 tahun mayoritas mengalami depresi ringan. Subyek perempuan lebih banyak mengalami depresi dibandingkan laki-laki. Subyek dengan pola belajar sedang yang mengalami depresi ringan sebanyak $17,6 \%$ dan subyek dengan pola belajar berat yang mengalami depresi ringan sebanyak 20,7\%.

Kesimpulan: Penelitian ini menyimpulkan bahwa tingkat depresi yang dominan adalah depresi ringan.

Kata kunci: deskriptif, depresi, prevalensi depresi, mahasiswa kedokteran

Cite Pasal Ini: Indira, A.T., Sawitri, A.A.S., Ariastuti, L. 2020. Prevalensi depresi pada mahasiswa Program Studi Pendidikan Dokter semester III dan V di Fakultas Kedokteran Universitas Udayana tahun 2017. Intisari Sains Medis 11(2): 892-895. D0I: 10.15562/ism.v11i2.211

\section{PENDAHULUAN}

Depresi biasanya dikaitkan dengan emosi karena kesedihan maupun duka mendalam, namun rasa sedih maupun duka tersebut tidak berkurang ketika penyebab eksternal dari emosi tersebut hilang, dan emosi tersebut biasanya tidak sebanding dengan penyebabnya. Diagnosis penyakit depresi biasanya didukung oleh gejala-gejala seperti perubuahan suasana hati, ditandai dengan kesedihan atau cepat marah disertai beberapa perubahan fisiologis seperti gangguan pada tidur, gangguan makan, gangguan kebutuhan seksual, sembelit, rasa ingin bunuh diri, serta melambatnya cara berbicara dan 
bertindak. Perubahan ini harus tetap ada selama 2 minggu dan mengganggu pekerjaan serta keluarga maupun orang terdekat. ${ }^{1}$

Kejadian depresi meningkat sangat pesat, dan menempati urutan keempat dalam daftar penyakit gangguan jiwa terberat di seluruh dunia. Berdasarkan definisi umum, kejadian depresi di Amerika Serikat lebih dari 12\% pada pria dan $20 \%$ pada wanita. ${ }^{1}$ Tingkat depresi pada dewasa maupun remaja meningkat sangat drastis di setiap tahunnya. Depresi dua kali lebih mungkin dan lebih berat pada wanita dewasa dibandingkan pada pria dewasa. Temuan ini tidak berlaku sampai pertengahan masa remaja. Penelitian mengenai depresi pada masa remaja menunjukkan bahwa depresi adalah salah satu gangguan mental yang paling umum di kalangan remaja. Sekitar 20\% mengalami gangguan depresi mayor (MDD) dan 15\% mengalami depresi ringan. ${ }^{3}$

Durasi rata-rata episode depresi pada anakanak dan remaja adalah sekitar 9 bulan. Namun, $70 \%$ pasien memiliki gejala hingga waktu 5 tahun, yang merupakan pengembangan episode depresi berikutnya. Penelitian juga menunjukkan adanya kontinuitas antara depresi masa kanak-kanak dengan depresi yang dialami di masa dewasa. ${ }^{4}$ Depresi pada remaja meningkatkan risiko percobaan bunuh diri, penyalahgunaan zat, masalah akademik, perilaku antisosial, dan masalah interpersonal. ${ }^{3}$

Depresi merupakan hal yang sangat rentan terjadi pada mahasiswa. Perubahan lingkungan belajar merupakan salah satu yang menjadi pencetus depresi pada mahasiswa. Prevalensi depresi pada mahasiswa di Indonesia dilaporkan lebih tinggi dari populasi umum. ${ }^{5}$ Berdasarkan survei pendahuluan pada 10 orang mahasiswa Fakultas Kedokteran Universitas Udayana, ditemukan 2 orang mahasiswa yang pernah mengalami gejala depresi seperti kurang nafsu makan, sulit tidur, dan malas untuk melakukan kegiatan apapun. Maka dari itu penelitian ini ditujukan untu mengetahui prevalensi depresi pada mahasiswa Program Studi Pendidikan Dokter angkatan 2015 dan 2016 di Fakultas Kedokteran Universitas Udayana Denpasar.

\section{BAHAN DAN METODE}

Penelitian ini menggunakan rancangan deskriptif dengan pendekatan kuantitatif, dengan desain cross-sectional. Penelitian ini dilakukan di Fakultas Kedokteran Universitas Udayana pada bulan Juli - November 2017. Sampel dipilih dari mahasiswa Program Studi Pendidikan Dokter semester III dan V di Fakultas Kedokteran Universitas Udayana. Jumlah sampel yang terpilih sebanyak 87 orang yang dipilih menggunakan teknik simple random sampling. Mahasiswa yang telah memenuhi kriteria inklusi dan eksklusi akan disuruh mengisi kuesioner Beck Depression inventory (BDI) dan kuesioner pola belajar. Data pada penelitian ini dianalisis secara deskriptif univariat, menggunakan komputer, dan disajikan dalam bentuk tabel.

\section{HASIL}

Karakteristik demografi subyek disajikan pada Tabel 1. Tabel tersebut menunjukkan rerata usia subyek adalah 19,2 tahun dengan mayoritas perempuan sebanyak 52 orang (59.77\%). Subyek lebih banyak memiliki pola belajar berat (keras), yakni sebanyak 53 orang (60.92\%). Tidak ada mahasiswa FK yang memiliki pola belajar ringan.

\section{Prevalensi depresi dan karakteristik depresi berdasarkan umur, jenis kelamin dan pola belajar}

Jika ditinjau dari tingkat keparahan depresi, mayoritas mahasiswa Program Studi Pendidikan Dokter, Fakultas Kedokteran Universitas Udayana semester III dan V tidak mengalami depresi (64.3\%). Dari mereka yang mengalami depresi, mayoritas mengalami depresi ringan adalah sebesar 19.54\%, dan depresi sedang sebesar $10.34 \%$. Keadaan depresi berat memiliki prevalensi paling sedikit, yaitu sebesar $5.75 \%$.

Pada tabel selanjutnya menyajikan gambaran depresi mahasiswa berdasarkan karakteristik umur, jenis kelamin dan pola belajar.

Jika dilihat berdasarkan jenis kelamin, pada laki-laki lebih banyak tidak mengalami depresi; sehingga lebih sedikit yang mengalami depresi ringan, sedang dan berat dibandingkan dengan perempuan. Perbedaan prevalensi antara lakilaki dan perempuan cenderung lebih tinggi pada depresi sedang dan depresi berat.

Jika dilihat berdasarkan pola belajar, tidak ditemukan mahasiswa dengan pola belajar ringan. Pada mahasiswa dengan pola belajar sedang, mayoritas mahasiswa tidak mengalami depresi (normal), diikuti oleh depresi ringan, depresi berat, dan sedang.

Pada mahasiswa dengan pola belajar berat, mayoritas tidak mengalami depresi (normal). Sedangkan mahasiswa yang mengalami depresi ringan lebih banyak dibandingkan dengan yang mengalami depresi sedang dan berat. Jika dilihat berdasarkan usia, pada mahasiswa yang berusia $<19$ tahun mayoritas tidak mengalami depresi (normal). Sedangkan mahasiswa yang mengalami depresi ringan lebih banyak pada usia $<19$ tahun dibandingkan dengan usia $>19$ tahun. 
Tabel 1 Karakteristik subyek

\begin{tabular}{lcc}
\hline Variabel & Frekuensi $(\mathbf{n = 8 7})$ & Persentase (\%) \\
\hline Usia (Rerata \pm SD) & $19.2 \pm 0.96$ & $100 \%$ \\
Jenis kelamin & 35 & \\
$\quad$ Laki-laki & 52 & $40.23 \%$ \\
$\quad$ Perempuan & & $59.77 \%$ \\
Pola belajar & 0 & \\
Ringan & 34 & $0 \%$ \\
Sedang & 53 & $39.08 \%$ \\
Berat & & $60.92 \%$ \\
\hline
\end{tabular}

Tabel 2 Prevalensi depresi berdasarkan derajat keparahan

\begin{tabular}{lcc}
\hline Variabel & Frekuensi $(\mathbf{n = 8 7})$ & Persentase $(\%)$ \\
\hline Status depresi & & \\
Tidak depresi & 56 & $64.37 \%$ \\
Depresi & 31 & $35.63 \%$ \\
ringan & 17 & $19.54 \%$ \\
sedang & 9 & $10.34 \%$ \\
berat & 5 & $5.75 \%$ \\
\hline
\end{tabular}

\section{Tabel 3 Gambaran depresi berdasarkan umur, jenis kelamin, dan pola belajar}

\begin{tabular}{|c|c|c|c|c|c|c|c|c|}
\hline \multirow[b]{3}{*}{ Variabel } & \multicolumn{8}{|c|}{ Tingkat Depresi } \\
\hline & \multicolumn{2}{|c|}{ Normal } & \multicolumn{2}{|c|}{ Ringan } & \multicolumn{2}{|c|}{ Sedang } & \multicolumn{2}{|c|}{ Berat } \\
\hline & $\mathbf{N}$ & $\%$ & $\mathbf{n}$ & $\%$ & $\mathbf{N}$ & $\%$ & $\mathbf{N}$ & $\%$ \\
\hline \multicolumn{9}{|l|}{ Jenis Kelamin } \\
\hline - Laki-laki & 25 & 71.4 & 8 & 22.9 & 1 & 2.3 & 1 & 2.3 \\
\hline - Perempuan & 31 & 59.6 & 9 & 17.3 & 8 & 15.4 & 4 & 7.7 \\
\hline \multicolumn{9}{|l|}{ Pola Belajar } \\
\hline - Sedang & 23 & 67.6 & 6 & 17.6 & 2 & 5.9 & 3 & 8.9 \\
\hline - Berat & 33 & 62.3 & 11 & 20.7 & 7 & 13.2 & 2 & 3.8 \\
\hline \multicolumn{9}{|l|}{ Usia } \\
\hline$-\quad \leq 19$ tahun & 35 & 66 & 9 & 17 & 6 & 11.3 & 3 & 6.4 \\
\hline$-\quad>19$ tahun & 21 & 61.8 & 8 & 23.5 & 3 & 8.8 & 2 & 5.9 \\
\hline
\end{tabular}

\section{PEMBAHASAN}

Pada penelitian ini didapatkan mayoritas mahasiswa Program Studi Pendidikan Dokter Fakultas Kedokteran (FK) Universitas Udayana semester III dan $\mathrm{V}$ tidak mengalami depresi (normal), yaitu sekitar 64\%. Sedangkan jika dibandingkan antara depresi sedang, ringan, dan berat, didapatkan bahwa kategori depresi berat memiliki prevalensi paling kecil, yaitu sebesar 5,75\%. Temuan studi ini hampir serupa jika dibandingkan dengan studi serupa yang dilakukan di Faktultas Kedokteran Universitas Katolik Atma Jaya, yang mendapatkan prevalensi mahasiswa tidak mengalami depresi sebanyak $65,1 \%{ }^{5}$ Namun jika dibandingkan di antara kelompok yang mengalami depresi, terlihat bahwa mahasiswa di FK Universitas Udayana lebih banyak yang mengalami depresi sedang dan berat dibandingkan mahasiswa di FK Atmajaya. Perbandingan antara FK Universitas Udayana dan FK Atmajaya adalah: depresi ringan $19.54 \%$ vs. $28.6 \%$, depresi sedang $10.34 \%$ vs. $6.3 \%$, dan depresi berat $5.75 \%$ vs. $0 \%{ }^{5}$ Perbedaan kedua temuan ini, terutama pada prevalensi depresi berat, bisa disebabkan oleh perbedaan sampel dan kuesioner yang digunakan.

Salah satu hal yang perlu diperhatikan adalah mahasiswa FK dalam studi kami mengakui memiliki pola belajar yang cenderung sedang hingga berat. Pada penelitian ini ditemukan mahasiswa dengan pola belajar berat memiliki kejadian depresi yang lebih tinggi dibandingkan mahasiswa yang memiliki pola belajar sedang.

Berdasarkan jenis kelamin, tingkat depresi ringan, sedang, dan berat lebih banyak terjadi pada perempuan dibandingkan dengan laki-laki. Pada studi epidemiologi ditemukan angka kejadian depresi lebih besar pada wanita dibandingkan pria. Salah satu penyebab hal tersebut adalah wanita memiliki siklus hormonal dengan kadar yang fluktuatif. Selain itu keadaan psikososial juga berperan penting. Keadaan psikososial yang dimaksud seperti perasaan berduka, keputusasaan, sindroma pasca-trauma, koping keluarga yang tidak efektif, dan keadaan sosial. ${ }^{6}$ Hal ini juga didukung hasil studi yang dilakukan oleh Hadianto dkk (2014), yang menunjukkan bahwa mahasiswa perempuan memiliki risiko dua kali lebih besar daripada mahasiswa laki-laki. ${ }^{5}$

Pada studi ini diperoleh hasil bahwa depresi terbanyak pada usia $\leq 19$ tahun. Pada studi lainnya, prevalensi kejadian depresi diperkirakan sekitar 2\% pada anak-anak (6-12 tahun) dan 2-8\% pada remaja (13-18 tahun), dengan puncak insidensi pada sekitar masa pubertas. ${ }^{4}$ Jika dikaitkan dengan hasil yang diperoleh peneliti, terdapat kesamaan rentang usia prevalensi depresi tertinggi antara hasil yang diperoleh peneliti dengan penelitian lainnya.

Secara keseluruhan, hasil studi yang diperoleh penulis sejalan dengan hasil studi yang dilakukan oleh peneliti lainnya pada mahasiswa kedokteran. Depresi dapat terjadi pada mahasiswa kedokteran, namun dengan tingkatan sedang, ringan, dan berat yang prevalensinya berbeda diantara studi yang ada. Sehingga, penanganan depresi di kalangan mahasiswa FK merupakan hal yang penting untuk dilakukan oleh mahasiswa yang bersangkutan maupun oleh pihak fakultas tempat mahasiswa menuntut ilmu. 


\section{SIMPULAN}

Prevalensi kejadian depresi sebesar $35.63 \%$ dan sebesar $5.57 \%$ dalam kategori berat. Proporsi depresi berat lebih banyak ditemukan pada mahasiswa FK Universitas Udayana dengan jenis kelamin perempuan, pola belajar sedang dan usia $\leq 19$ tahun. Depresi sedang (10.35\%) lebih banyak ditemukan pada mahasiswa dengan jenis kelamin laki-laki, pola belajar berat, dan usia $\leq 19$ tahun. Depresi ringan (19.54\%) lebih banyak ditemukan pada mahasiswa dengan jenis kelamin laki-laki, pola belajar berat, dan usia $>19$ tahun.

\section{DAFTAR PUSTAKA}

1. Belmaker R, Agam G. Mechanisms of disease: major depressive disorder. The New England Journal of Medicine. 2008. Hal. 55-68.

2. Shin KM, Cho SM, Shin YM, Park KS. Early risk factors for depressive symptoms among Korean Adolescents: A 6-to-8 Year Follow-up Study. The Korean Academy of Medical Sciences. 2013; 1667-71.
3. Rohde P, Stice E, Gau J. Effects of three depression prevention interventions on risk for depressive disorder onset in the context of depression risk factors; 2013: Hal. 584-93.

4. Bin Q, Xinyu Z, Kurt D, Yiyun L, Craig W, David C, Yuqing Z, Peng X. Psychotherapy for depression in childrenand adolescents: study protocol for a systematic review and network meta-analysis; 2014: Hal. 1-7.

5. Hadianto H. Prevalensi dan faktor resiko yang berhubungan dengan tingkat gejala depresi pada mahasiswa Program Studi Pendidikan Dokter Fakultas Kedokteran Universitas Tanjungpura; 2014.

6. Hirschfeld RMA \& Weissman MM. Depression and bipolar disorder. Neuropsychopharmacology. 2010; 167: pp.1254-1263.

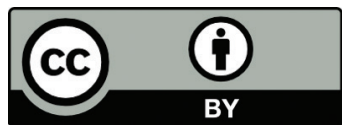

This work is licensed under a Creative Commons Attribution 